\title{
ANÁLISE DO IC E DO ICP NA UNIDADE DE GERENCIAMENTO DE RECURSOS HÍDRICOS DOS RIOS PIRACICABA, CAPIVARI E JUNDIAÍ
}

\author{
Sabrina Lais Basso ${ }^{(a)}$, Ana Claudia Bento ${ }^{(b)}$, Janete da Silva ${ }^{(c)}$, Jonas Teixeira Nery ${ }^{(d)}$ \\ (a) Instituto de Ciência e Tecnologia, UNESP Sorocaba, bassolais@ gmail.com \\ (b) Instituto de Ciência e Tecnologia, UNESP Sorocaba, anacbento@ outlook.com \\ (c) Instituto de Ciência e Tecnologia, UNESP Sorocaba, janecarlota@yahoo.com.br \\ (d) UNESP Ourinhos, jonas@ ourinhos.unesp.br
}

\section{EIXO: BACIAS HIDROGRÁFICAS E RECURSOS HÍDRICOS: ANÁLISE, PLANEJAMENTO E GESTÃO}

\section{Resumo}

A precipitação pluvial na Unidade de Gerenciamento de Recursos Hídricos dos rios Piracicaba, Capivari e Jundiaí é analisada através de auxílio de índices pluviometricos: índice de concentração (IC) e índice de concentração de precipitação (ICP). Foram calculados através do software R com as funções precintcon.ci.analysis e precintcon.pci.analysis, para a escala temporal de 1976 a $2010 \mathrm{com}$ base nos dados obtidos pela Agência Nacional de Águas (ANA), totalizando 22 séries pluviométricas distribuídas na unidade ou próxima. Obteve-se assim o estudo em diferentes escalas temporais, considerando as decorrências dos eventos ENOS e interferência no padrão de chuvas na Unidade. Os resultados obtidos com os índices mostram a variabilidade da precipitação pluvial e possibilita pensar a suscetibilidade erosiva da UGRHI -5

Palavras chave: UGRHI-5; precipitação; IC; ICP

\section{Introdução}

O gerenciamento das bacias hidrográficas, embora tenha avançado muito nesses últimos anos, ainda é bastante incipiente para os impactos sócio-ambientais urbanos em diversas cidades brasileiras. O modelo de impermeabilização excessiva do solo com a dinâmica inapropriada do uso e ocupação do solo nessas áreas, acarretam problemas crônicos à população, como riscos de enchentes, agravados por episódios anômalos de precipitação ou falta de água em épocas prolongadas de estiagem, aliados a má qualidade dos rios que atravessam essas áreas populosas e industrializadas.

As bacias hidrográficas situadas em regiões com grandes concentrações urbano industrial, apresentam sérios problemas de degradações desses recursos e muitos conflitos pelo uso da água, o que ocorre com a UGRHI-5,cuja interdependência levou ao agrupamento em uma única Unidade de Gerenciamento de Recursos Hídricos: as bacias dos rios Piracicaba, Capivari e Jundiaí. A UGRHI-5 sofre influência direta da expansão urbano-industrial da Grande São Paulo, com limite de disponibilidade hídrica ultrapassada. As bacias encontram-se impactadas por lançamentos industriais e urbanos-muitos clandestinos. $\mathrm{O}$ entorno 
apresenta um considerável número de favelas e altos índices de analfabetismo (Neves, 2007). A UGRHI-5 situa-se em uma área de transição climática, onde atuam diferentes sistemas atmosféricos tropicais e extratropicais, o que resulta em uma grande complexidade atmosférica de difícil previsão (Filho, 2006). A natureza das chuvas dificulta a tomada de medidas para prevenção, absorção e minimização dos impactos associados. Com a disponibilidade hídrica superficial em baixa, a procura por água subterrânea vem aumentando consideravelmente, utilizada como uma fonte alternativa e suplementar para abastecimento,principalmente industrial, mesmo em áreas já atendidas pela rede de abastecimento público (Neves, 2007). Portanto esse trabalho tem como objetivo analisar os índices de concentração (IC) e de concentração da precipitação (ICP) na UGRHI 5, corelacionando esses resultados com as áreas de suscetibilidade errosiva desta unidade.

Em 1993, houve a criação do Comitê de Bacias Hidrográficas dos Rios Piracicaba, Capivari e Jundiaí CBHPCJ, composto por representantes do Estado, dos municípios e da Sociedade Civil e, em 2009, foi criada a Fundação Agência das Bacias PCJ, que desde 2012 conta com profissionais especializados na gestão de recursos hídricos, mas apesar da fundação, comitê e de uma sociedade civil bastante participativa, ainda há municípios não cadastrados nas redesde água e esgotos e a implementação de políticas públicas de prevenção e minimização dos problemas, ainda são deficientes devido à vários fatores institucionais, como pela falta de entendimento da complexidade dos modelos de precipitações em áreas densamente ocupadas, seguido do delineamento de processos espaço - temporais físicos e antrópicos sob o contexto analítico para tomadas de decisões.

\subsection{Caracterização geral da UGRHI - 5}

Este trabalho apresenta como área de estudo a unidade de Gerenciamento de Recursos Hídricos (UGRHI-5). Essa Unidade localiza-se na região leste do estado de São Paulo, desde a divisa com o estado de Minas Gerais até o Reservatório da Usina de Barra Bonita, no rio Tietê, numa extensão retilínea de, aproximadamente, $230 \mathrm{~km}$ (Figura1).

A bacia conjunta dos rios Piracicaba, Capivari e Jundiaí, os últimos afluentes do Médio Tietê, estende-se por $14.042,64 \mathrm{~km}^{2}$ em território paulista, sendo $11.313,31 \mathrm{~km} 2$ correspondentes à Bacia do Rio Piracicaba, 1.611,68 $\mathrm{km}^{2}$ correspondentes à bacia do rio Capivari e 1.117,65 $\mathrm{km}^{2}$ correspondentes à bacia do rio Jundiaí. As três bacias desenvolvem-se paralelamente no sentidoleste/oeste (Conselho Estadual de Recursos Hídricos, 2000).

A bacia do rio Piracicaba apresenta um desnível topográfico de cerca de 1.400 metros em uma extensão da ordem de $370 \mathrm{~km}$, desde suas cabeceiras na serra da Mantiqueira, no estado de Minas Gerais, até sua foz 


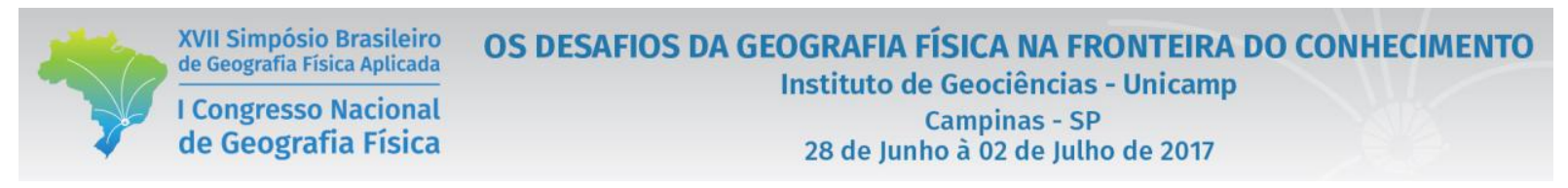

no rio Tietê. O desnível topográfico da bacia no rio Capivari é pequeno, não ultrapassando $250 \mathrm{~m}$ em um percurso de $180 \mathrm{~km}$, desde as suas nascentes na serra do Jardim, em altitude de $750 \mathrm{~m}$.

O rio Jundiaí, com suas nascentes a $1.000 \mathrm{~m}$ de altitude na serra da Pedra Vermelha, município de Mairiporã, apresenta desnível topográfico total emtorno de 500 m, em uma extensão aproximada de 110 $\mathrm{km}$.

Os principais formadores do rio Piracicaba são os rios Atibaia e Jaguari, este com a contribuição do rio Camanducaia. Os principais contribuintes do rio Capivari são o Córrego São Vicente e o rio CapivariMirim. Do rio Jundiaí, o principal tributário é o rio Jundiaí-Mirim.

As principais cidades localizadas na UGRHI-5 são: Campinas, Piracicaba, Jundiaí, Limeira, Americana, Sumaré, Santa Bárbara d'Oeste e Rio Claro.

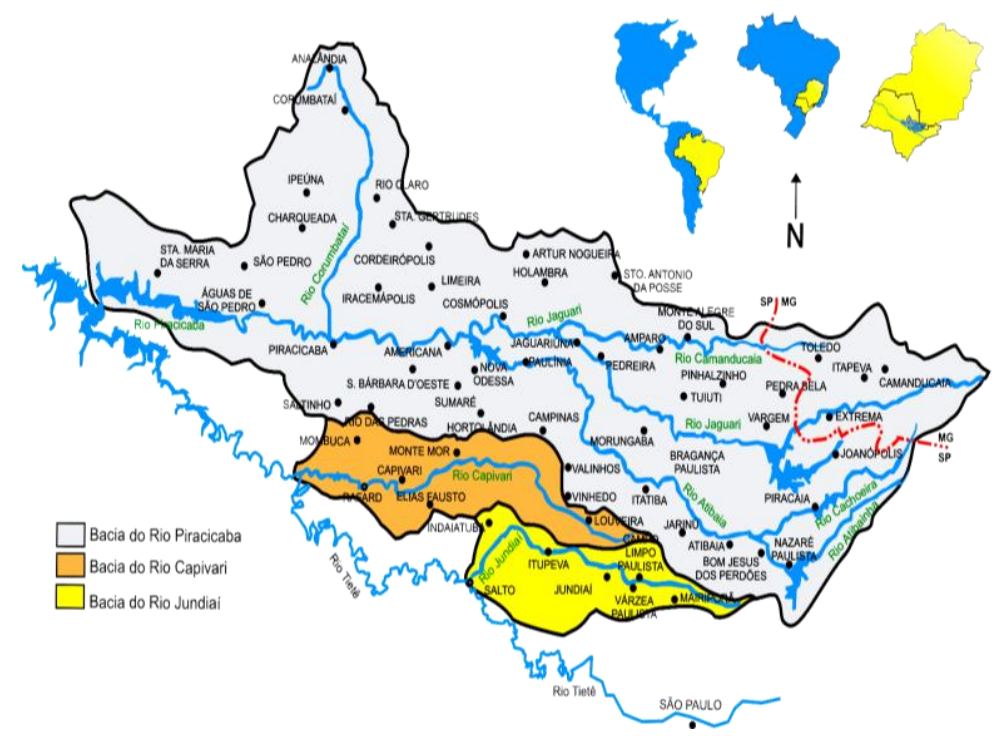

Figura 1: UGRHI-5 e suas bacias: Piracicaba, Capivari e Jundiaí, SP

A UGRHI-5 limita-se ao norte com a UGRHI-9, da bacia hidrográfica do rio Mogi-Guaçu, a leste com o estado de Minas Gerais, a sudeste com a UGRHI-2, da bacia hidrográfica do rio Paraíba do Sul, ao sul com a UGRHI-6, da bacia hidrográfica do Alto Tietê, a oeste com a UGRHI-10, da bacia hidrográfica do rio Sorocaba e Médio Tietê e, a noroeste, com a UGRHI-13, da bacia hidrográfica do Tietê/Jacaré.

Procura-se esboçar as variabilidades de precipitação da Unidade de Gerenciamento de Recursos Hídricos dos Rios Piracicaba, Capivari e Jundiaí (UGRHI - 5). 
XVII Simpósio Brasileiro

de Geografia Fisica Aplicada

I Congresso Nacional

de Geografia Física
OS DESAFIOS DA GEOGRAFIA FÍSICA NA FRONTEIRA DO CONHECIMENTO

Instituto de Geociências - Unicamp

Campinas - SP

28 de Junho à 02 de Julho de 2017

\section{Procedimentos metodológicos}

Os dados pluviométricos utilizados das 22 séries pluviométricas localizadas na UGRHI-5 e entorno, observa-se a distribuição espacial das estações na Figura 2. Os dados foram obtidos da base de dados da Agência Nacional de Águas (ANA), através de seu site HIDROWEB (www.ana.gov.br/hidroweb). Os mapas foram elaborados no software Golden Surfer® 8 através das latitudes e longitudes de cada uma das séries pluviométricas selecionadas anteriormente.
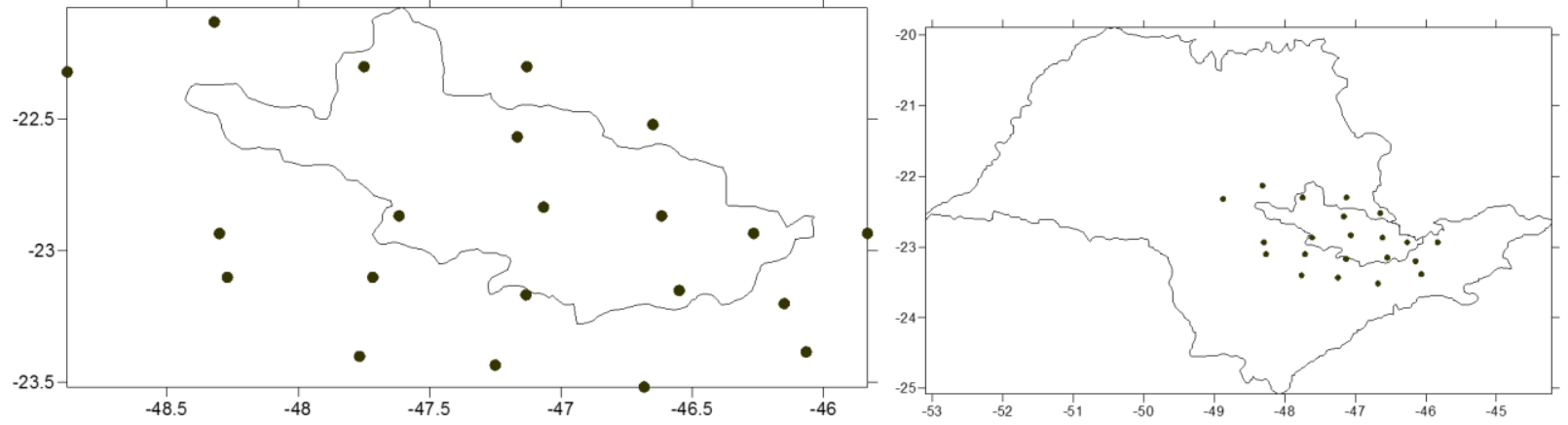

Figura 2: localização das 22 estações dispostas na UGRHI e no estado de São Paulo

Os dados obtidos no sítio HIDROWEB foram organizados em planilhas no Microsoft Excel 2010, para posteriormente desenvolver os cálculos dos índices. A organização constitui-se na conferência dos dados das 22 séries pluviométricas, no intuito de verificação de prováveis falhas de coleta e estruturação do arquivo para elaboração dos cálculos dos índices IC (Índice de Concentração) e ICP (Índice de Concentração de Precipitação) através do software R 3.3.1 através da função precipticon desenvolvida por POVOA e NERY (2016). O índice IC foi calculado através da função precintcon.ci.analysis, já o índice ICP por meio de precintcon.pci.analysis. Calculou-se também a média da precipitação para a unidade de gerenciamento. Em seguida os cálculos, os dados obtidos foram analisados e organizados novamente em planilhas no Microsoft Excel, para a confecção do produto final, mapas e tabelas para cada período espacial e temporal selecionado.

\section{1. Índices calculados}

\subsection{1. Índice de Concentração (IC)}

O índice IC analisa a irregularidade da precipitação em uma área através da modelação espacial dos resultados obtidos por meio dos métodos de interpolação univariadas e multivariadas proposto por MARTÍN-VIDE (2004) no trabalho sobre a Península Ibérica com nove séries pluviométricas de Portugal. É considerado o trabalho pioneiro sobre o Índice de Cocentração. O autor apresentou a técnica e a aplicação dos dados pluviométricos diários que foram utilizados em seus estudos, portanto compreende-se 
que o IC é um importante índice para determinar o grau de regularidade da distribuição da precipitação ao longo de uma série temporal.

Os autores SANTOS e FRAGOSO (2010) afirma que para o cálculo do índice IC dispõem-se de séries longas de dados, assim para o cálculo do índice para as 22 estações supracitadas foi estabelecido um período de 35 anos, entre o ano de 1976 - 2010. Já os autores PATELA e SHETE (2015) colocam que esses índices possibilitam identificar o impacto porcentual da precipitação.

Este método de calcular o IC foi realizado por Martín-Vide em estudos na costa mediterrânea espanhola, (1994) e para a região da Espanha peninsular no ano de 2004, possibilitando a constatação da intensidade de precipitação e erosividade do local, assim o autor afirma que o índice IC é um excelente indicador de intensidade e erosividade.

O IC consiste em valores entre 0 e 1, obedecendo a ordem que quanto mais próximo de zero, melhor é a distribuição da precipitação no espaço e quanto mais próximo de 1 o resultado do IC se constitui mais a chuva daquela localidade tende a está concentrada em poucos espaços.

\subsection{2 Índice de Concentração de Chuva (IPC)}

O Índice de Concentração de Chuva proposto por Oliver em 1980, com a finalidade de determinar a variabilidade temporal da distribuição de chuvas ao longo dos anos, portanto o índice se baseia na distribuição mensal de chuvas, onde os valores das distribuições mensais idênticas serão idênticos para as quantidades diferentes, (De LUIS, et al. 1997). Deste modo o índice é recomentado para obtenção de dados para ter informação sobre a variabilidade total da precipitação em um determinado do período temporal, sendo calculado em escalas anuais e sazonais. Segundo De LUIS et al. (2011), o ICP é classificado como apresenta-se na Tabela 1 .

Tabela 1: Classificação do índice ICP.

\begin{tabular}{cc}
\hline ICP & PRECIPITAÇÃO (mensal) \\
\hline$\leq 10 \%$ & Uniforme \\
$11 \%$ a $15 \%$ & Moderadamente sazonal \\
$16 \%$ a $20 \%$ & Sazonal \\
$\geq 20 \%$ & Irregular \\
\hline
\end{tabular}

Fonte: Luis et al. (2011), organizado pelas autoras. 
Percebe-se que o índice ICP é um importante meio de observar a distribuição da precipitação, De LUIS et al. (2011) elenca que o índice permite inferência sobre o comportamento da concentração da chuva em um espaço. Assegura também que como a chuva tem uma influência direta com a recarga e fluxo das águas subterrâneas, o conhecimento espacial e concentração da mesma se torna indispensável.

\section{Resultados e discussões}

A análise estatística da precipitação da Unidade de Gerenciamento consistir nas 22 séries pluviométricas da UGRHI-5 com o propósito de identificar as variabilidades presentes através dos índices IC e ICP. Os resultados mostram que a variabilidade da precipitação de chuvas no território da UGRHI-5 para cada índice abordado possibilita ponderar sobre sua variabilidade do regime de chuva, a chuva é de extrema importância para o reabastecimento das águas subterrâneas e do ciclo hidrológico de uma região, uma vez que o seu regime pode ter eventos extremos (máxima e mínima) que interferem diretamente nos seres vivos e no planeta como um todo, sobressaindo à relação homem-meio e meio-homem que são dependente e refém do regime pluviométrico de uma região, na unidade de estudo a precipitação pluviométrica situam-se na média de 1.200 e 1.800 mm anuais para o período estudado (1976 à 2010).

Destaque-se que os anos com atuação do fenômeno El Niño - Oscilação Sul (ENOS), no estado de São Paulo tem como característica ser muito úmido. Isso ocorre devido ao fenômeno ocorrer no verão aumentando a temperatura acima do normal, o que favorece a formação de nuvens e subsequente a ocorrência de precipitação pluvial.

O Índice de Concentração calculado para a UGRHI-5 no período supracitado apresentou valores entre 0.49 a 0.55 . Observa-se na Figura 3 os resultados obtidos, que serão apresentados por anos previamente selecionados que tiveram ocorrência de ENOS, nas fases frias e quentes. Os anos selecionados para análise do índice foram os anos de 1976, 1983 e 1997, respectivamente La Niña e os dois últimos anos El Niño, ambos com intensidade forte e o ano de 2010 que teve ocorrência de El Niño de intensidade fraca. A intensidade classificada como forte não significa que a ocorrência do ENOS tenha afetado todas as regiões do planeta de forma e intensidade igual e sim que um ENOS considerado forte para uma região pode não ter atingido outras regiões com a mesma intensidade.

Observa-se que na Figura 3 que o ano de 1976 (Figura 3a) que o IC é em média de 0.51 na UGRHI e ao sul nota-se o aumento da variação neste ano. No ano de 1983 (Figura 3b) o IC varia de 0.49 a 0.55 demostrando que a concentração de chuvas neste ano de El Niño de intensidade forte teve distribuição uniforme na Unidade, todavia apresenta algumas concentrações. No ano de 1997 (Figura 3c) os resultados obtidos mostram que o índice para o leste da Unidade teve maiores resultados chegando a IC de 0.56. Já 


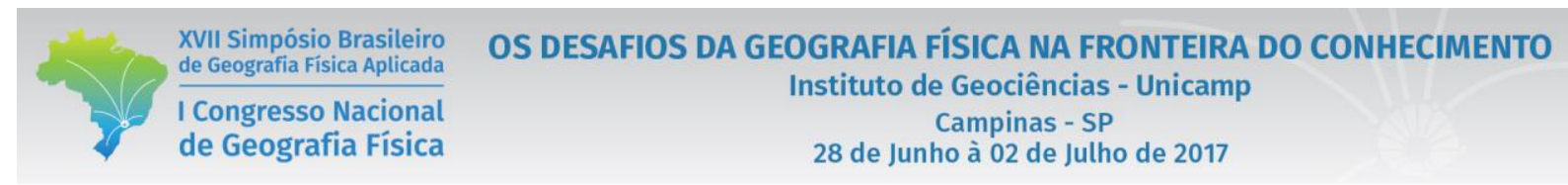

para o ano de 2010 (Figura 3d) de El Niño intensidade fraca a variação dos resultados são pequenas, mostra que a precipitação pluviométrica na UGRHI-5 constituiu em toda área da Unidade. Por fim percebe-se que as estações da UGRHI-5 apresentam valores entre 0.49 e não ultrapassam 0.60 do índice de concentração, o que possibilita afirmar que a Unidade apresenta regularidade das chuvas. O índice ICP permite determinar a variabilidade temporal da distribuição da precipitação pluvial ao longo dos anos.

a)

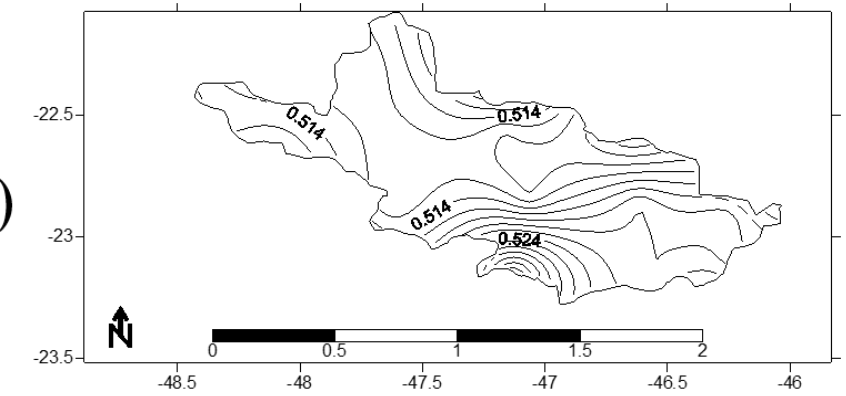

b)

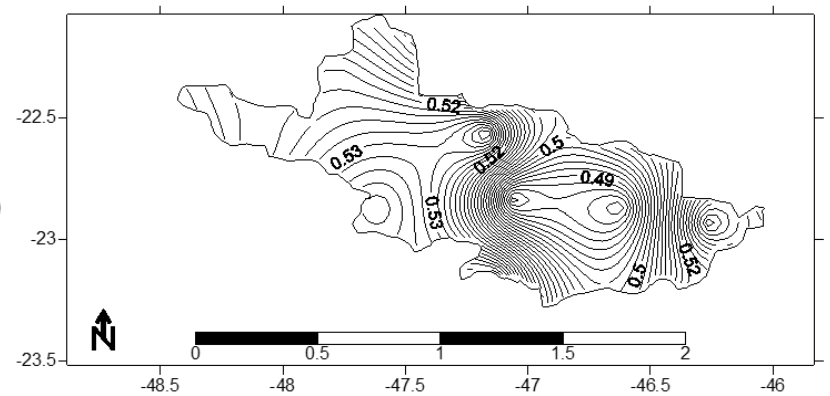

c)
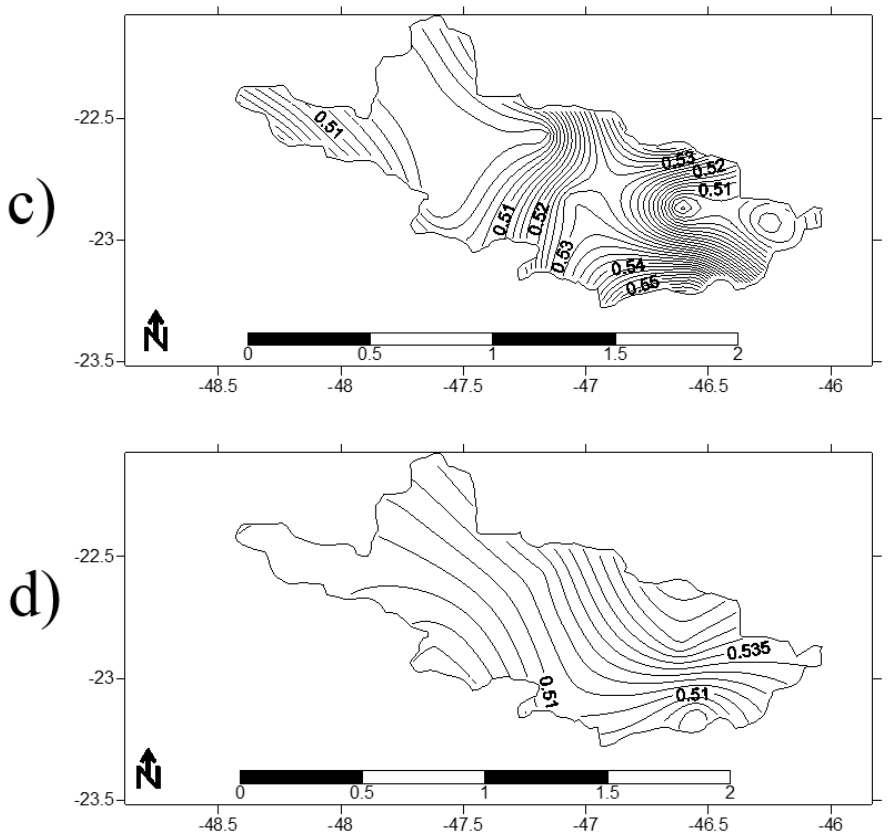


\section{OS DESAFIOS DA GEOGRAFIA FÍSICA NA FRONTEIRA DO CONHECIMENTO \\ Instituto de Geociências - Unicamp \\ Campinas - SP \\ 28 de Junho à 02 de Julho de 2017}

Figura 3: Resultados do Índice de Concentração para a UGRHI 05. a) 1976; b) 1983; c) 1997 e d) 2010.

$\begin{array}{lr}\text { Na Figura } & 4 \\ \text { resultados } & \text { do } \\ \text { unidade } & \text { de } \\ \text { dos } & \text { Rios } \\ \text { Capivari } & \text { e }\end{array}$

(UGRHI-05). a)

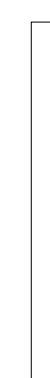

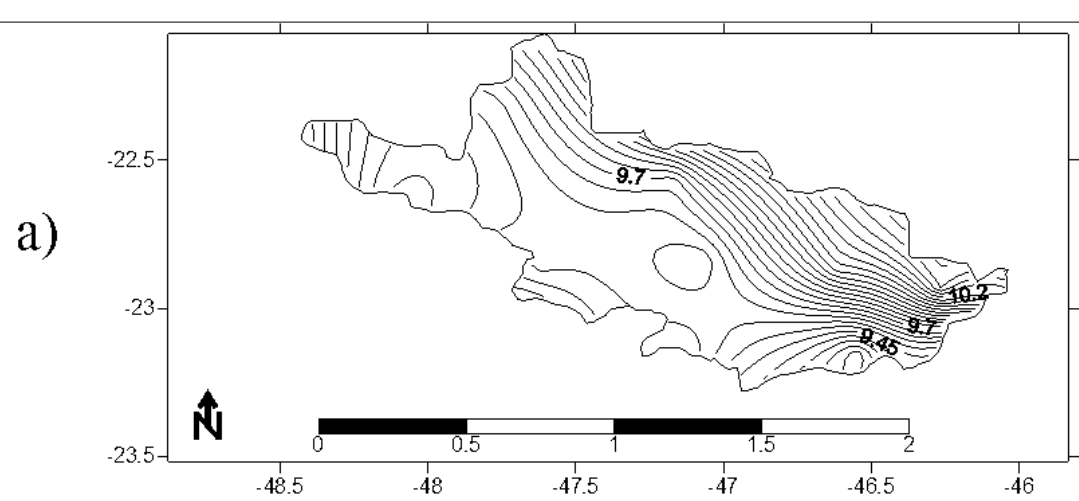

observam-se os

ICP para a gerenciamento

Piracicaba, Jundiaí

b)

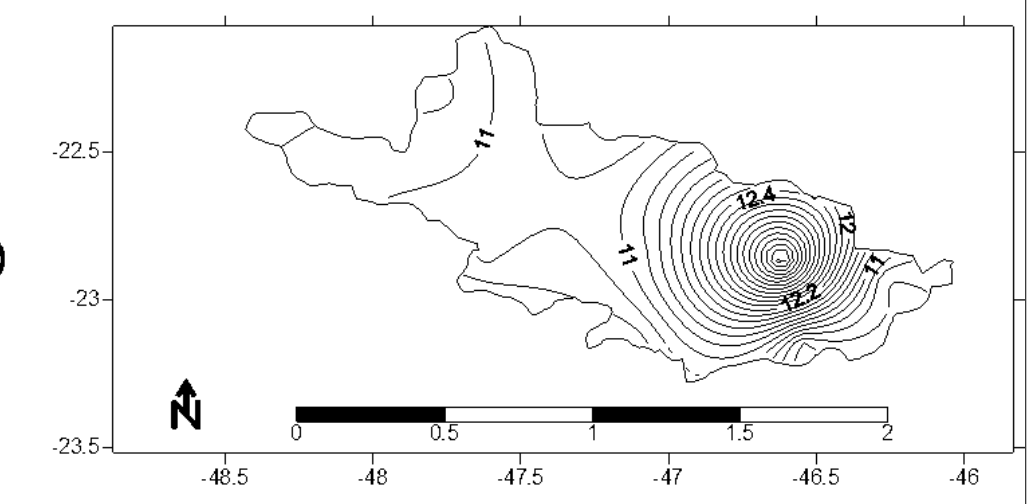

c)

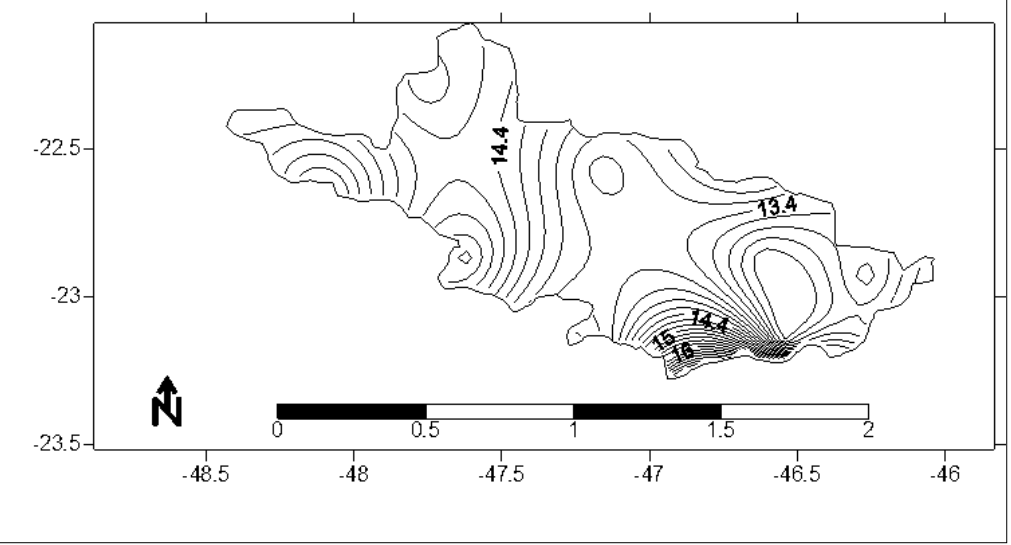


Figura 4: Resultados do índice de Concentração para a UGRHI 05. a) 1976; b) 1983 e c) 1997.

Segundo a classificação proposta por Luis et al. (2011) o ICP varia entre valores menores a $10 \%$ a superior a $20 \%$ sendo classificada a precipitação pluvial em uniforme, moderada, sazonal e irregular.

Na Figura 4 observa-se o índice ICP para o ano de 1976 (Figura 4a) sendo os valores menores a $10 \%$ o que classfica a chuva neste ano na Unidade de Gerenciamento como sendo uniforme em toda área. No ano de 1983 (Figura 4b) o ICP apresenta valores entre $11 \%$ a $15 \%$ sendo classificada como precipitação moderada ao longo do ano, observa-se que o lado leste da Unidade apresenta os valores mais altos, com algumas concentrações em relação a Unidade de Gerenciamento, lembra-se que neste ano de El Niño de intensidade forte. No ano de 1997 (Figura 4c) os resultados obtidos mostram que o índice ICP para o sul e leste da Unidade teve maiores resultados, varia-se entre $13.4 \%$ e valores superiores a $16 \%$, ou seja, a precipitação foi moderada e sazonal, os maiores ICP (superiores a $16 \%$ ) encontra-se na porção sudeste da unidade.

Com os dados obtidos com os índices IC e ICP pode-se avaliar os risco de erosão da Unidade de Gerenciamento dos dos rios Piracicaba, Capivari e Jundiaí. Segundo LOMBARDI NETO, F. \& PASTANA (1972, p. 233) a chuva tem capacidade de causar erosão no solo dependendo da sua intensidade, quantidade e as condições que o solo se encontra, afirmam que a "chuva de longa duração e baixa intensidade pode ocasionar perdas de água com pequeno risco de erosão, enquanto chuva de menor quantidade e alta intensidade pode condicionar maior risco, ou seja, se a precipitação for concentrada ou irregular a probabilidade de ocasionar erosão é maior. Deste modo com o auxílio da Figura 5, que mostra a suscetibilidade erosiva da Unidade de estudo e com o auxílio dos dados do CI e ICP percebe-se que a área da UGRHI-5 apresenta a suscetibilidade relativamente propicia a erosão, sendo a área central ao norte classifica como sendo de baixa suscetibilidade a erosão, o ponto mais crítico ao oeste da Unidade de Gerenciamento que é classificado com muito alta suscetibilidade a erosão por sulcos, ravinas e boçorocas, é a região das cidades de Rio Claro, Santa Maria da Serra e São Pedro. Perante os valores dos índices obtidos, pode-se considerar que áreas onde apresenta as maiores concentrações de chuva e irregularidade são nas regiões leste onde a suscetibilidade é alta e observa-se alguns pontos que estão presentes em áreas que tem muito alta a suscetibilidade a erosão. 


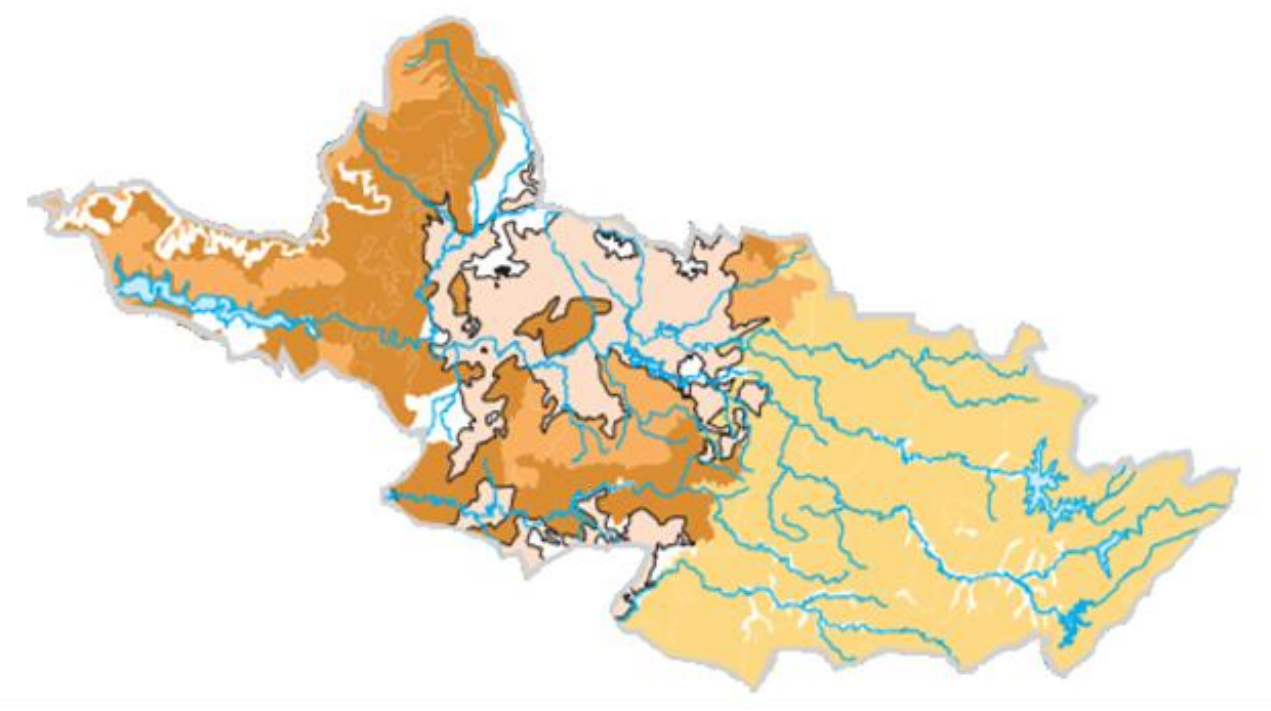

Muito alta suscetibilidade a erosão por sulcos, ravinas e boçorocas (rochas sedimentares/básicas)

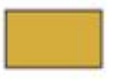

Alta suscetibilidade a erosão por sulcos, ravinas e boçorocas de grande porte (rochas cristalinas)

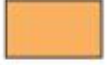

Alta suscetibilidade a erosão por sulcos, ravinas e boçorocas de grande porte (rochas sedimentares/básicas)

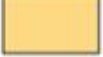

Alta suscetibilidade a erosão nos solos subsuperficiais (rochas cristalinas)

\section{Baixa suscetibilidade a erosão}

Figura 5: suscetibilidade erosiva da UGRHI-5

-Fonte: Instituto Geológico de São Paulo, editado pelas autoras.

\section{Considerações Finais}

Os índices IC e IPC foram calculados e analisados o que possibilitou determinar a variabilidade temporal da distribuição de chuvas ao longo dos anos delimitados. Percebeu-se que o regime de chuvas na UGRHI-5 teve distribuição moderada. Porém quando se observa a escala anual, o IPC encontrado para cada ano varia entre uniforme, irregular e sazonal, foi destacado alguns anos com máximas e mínimas e de ocorrência de fenômenos ENOS. O índice IC pelos anos trabalhados apresentou variação pequena, variando os valores entre 0.49 a 0.55 que determina que a chuva foi uniforme no unidade. 
Nesta escala temporal de 1976 a 2010 teve-se alguns eventos ENOS, fases frias (El Niño) e quentes (La Niña), que interferiram no regime de chuvas da Unidade.

Procurou-se verificar os efeitos destes eventos na Unidade e na suscetibilidade erosiva que a mesma apresenta, através disso aponta-se que a suscetibilidade vai de encontro com os pontos de concentração da chuva, necessitando de atenção e cuidados em períodos chuvosos.

\section{Bibliografia}

FILHO, A. P.; MATTOS, S. H. V. L.; ORSI, L.; VICENTE, A. K.; VICENTE, L. E. 2006. Monitoramento e gerenciamento de bacias urbanas associados a inundação: diagnose da bacia do Ribeirão quilombo na região metropolitana de Campinas utilizando geotecnologias. Revista do Departamento de Geografia, 19 (2006) $44-54$.

LOMBARDI NETO. F. \& PASTANA. F. I. Relação chuva-perdas por erosão. Bragantia. Boletim Científico do Instituto Agronômico do Estado de S. Paulo. Vol. 31. n 19. Campinas. Julho de 1972.

LUIS. M De; GONZÁLEZ-HIDALGO. J.C; RAVENTÓS. J.;SÁNCHEZ. J.R.; CORTINA.J. Distribución espacial de la concentración y agresividade de la luvia en el territorio de la comunidad Valenciana. Cuaternario y Geomorfologia. 11(3-4). 1997. p. 33-49

LUIS. M.; GONZÁLES-HIDALGO. J. C.; BRUNETTI. M.; LONGARES. L. A. Precipitation concentration changes in Spain 1946-2005. Natural Hazards and Earth System Sciences. Munich. v. 11. n. 5. p. $1259-1265$. 2011. http://dx.doi.org//10.5194/nhess-11- 1259-2011

MARTÍN-VIDE.J. Spatial distribution of a daily precipitation concentration index in peninsular spain. Internacional journal of Climatology. 2004 24. 959-971.

NEVES, M. A.; PEREIRA, S. Y. E FOWLER, H. G.2007. Impactos do sistema estadual de gerenciamento de recursos hídricos na bacia do Rio Jundiaí (SP). Ambiente \& Sociedade. Vol.10 no.2 Campinas.

PATELA. N.R.; SHETE. D.T. Analyzing Precipitation Using Concentration Indices for North Gujarat Agro Climatic Zone. India. N.R. Patel and D.T. Shete / Aquatic Procedia 4 ( 2015 ) 917 - 924.

POVOA. L. V.; NERY. J. T. (2016). precintcon: Precipitation Intensity. Concentration and Anomaly Analysis. R package version 2.2.1. Disponível em: <https://CRAN.R-project.org/package=precintcon>.

SANTOS. M.; FRAGOSO. M. Modelação espacial do índice de concentração diária de precipitação em Portugal Continental. VI Seminário Latino-Americano de Geografia Física. II Seminário Ibero-Americano de Geografia Física. Universidade de Coimbra. Maio de 2010

SÃO PAUlO (ESTADO), 2000.Conselho Estadual de Recursos Hídricos. Comitê das Bacias Hidrográficas dos Rios Piracicaba, Capivari e Jundiaí. Relatório de Situação dos Recursos Hídricos das Bacias dos Rios Piracicaba, Capivari e Jundiaí. Relatório zero. Piracicaba.

SÃO PAUlO (Estado). 2004. Conselho Estadual de Recursos Hídricos. Comitê das Bacias Hidrográficas dos Rios Piracicaba, Capivari e Jundiaí. Relatório de Situação dos Recursos Hídricos das Bacias dos Rios Piracicaba, Capivari e Jundiaí: Relatório um. Piracicaba: CBHPCJ. 